\title{
Study on the Propagation Law of Water Hammer Wave in Underwater Blasting and the Reducing Effect of Air Curtain on Water Hammer Wave
}

\author{
Chao Qi $\mathbb{D}^{1},{ }^{1}$ Zuxiang Hu ${ }^{\mathbb{D}}{ }^{1}$ Suihong Wang, ${ }^{2}$ Zhixiong Jiang $\mathbb{D}^{1},{ }^{1}$ Haoyuan Wu ${ }^{1}{ }^{1}$ \\ and Zhiqiang Yin $\mathbb{1}^{3}$ \\ ${ }^{1}$ School of Mining Engineering, Anhui University of Science and Technology, Huainan 232001, Anhui, China \\ ${ }^{2}$ Nuclear Industry Jingxiang Construction Group Co., Ltd., Huzhou 313000, Zhejiang, China \\ ${ }^{3}$ The Provincial Key Laboratory of Mining Effects and Disasters Preventing Under Deep Mining in Anhui, \\ Anhui University of Science and Technology, Huainan 232001, Anhui, China
}

Correspondence should be addressed to Zuxiang Hu; zxhu@aust.edu.cn and Zhiqiang Yin; zhqyin@aust.edu.cn

Received 4 March 2021; Revised 14 April 2021; Accepted 6 May 2021; Published 13 May 2021

Academic Editor: Bangbiao Wu

Copyright $(\odot 2021$ Chao Qi et al. This is an open access article distributed under the Creative Commons Attribution License, which permits unrestricted use, distribution, and reproduction in any medium, provided the original work is properly cited.

The harmful effects (water hammer wave, flying stone, and broken quality of concrete) produced in the process of underwater drilling and blasting are the key factors affecting the safety of underwater drilling and blasting. In fact, the harm caused by the water hammer wave is the most significant. As a consequence, it is of great significance to study the propagation law of water hammer waves. Based on the background of the cofferdam demolition project at the inlet section of Shibishan Central Canal in Ningguo City, China, a three-dimensional numerical model was established based on Coupled Eulerian-Lagrangian (CEL) method. Besides, the propagation law of water hammer waves at different water depths with different millisecond times was studied. Meanwhile, the reduction effect of the water hammer wave at different positions of the bubble curtain was analyzed. The results showed that, in the direction of the minimum resistance line of the charge, the attenuation law of the water hammer wave is accorded with the Cole formula and attenuated exponentially. The attenuation speed of the water hammer wave increased at first and then decreased with the increase of the millisecond time. In addition, the attenuation rate of the peak pressure was the fastest when the millisecond interval $30 \mathrm{~ms}$ was used. The attenuation of the water hammer wave at different water depths decreased at first and then decreased with the increase of water depth. The attenuation law of the water hammer wave decreased linearly with the increase of the distance between the bubble curtain and the charge. The research results can provide particular guiding significance for similar on-site construction.

\section{Introduction}

The tunnel intake cofferdam needs to be demolished after the tunnel inlet construction is completed to generate electricity from the tunnel inlet as scheduled. One-time demolition of the cofferdam by underwater millisecond blasting is the most commonly used method at present. Underwater millisecond blasting technology has been used in major civil projects in recent years, such as the blasting of the cofferdam of the Three Gorges Dam, the underwater blasting of the impenetrable wall of the upstream cofferdam of Gezhouba Hydropower Station, and the demolition of the intake cofferdam of the Qiandao Lake
Water Distribution Project. A series of harmful effects caused by underwater blasting technology (concrete crushing quality, water hammer wave and flying stone, etc.) have attracted the attention of many scholars with the popularization of underwater blasting technology. Water hammer wave is the most harmful.

In the past, many researchers have focused on the blasting parameters and initiation mode $[1,2]$, and the influence of porous fixed interval time and blockage length on adjacent structures in blasting aiming at the research on the propagation law of water hammer wave [3,4]. It mainly focuses on reducing regular air curtain layer position on water hammer wave in the 
aspect of air curtain $[5,6]$. However, the interval time of millisecond blasting affects the peak pressure of the water hammer wave in the process of underwater drilling millisecond blasting [7]. On the other hand, the reduction effect of bubble curtain is different at different distances from the charge [8]. It is of obvious practical significance to study the propagation law of water hammer waves according to the interval time of millisecond blasting and the different positions of the air curtain wall.

\section{State of the Art}

Many scholars have carried out numerical simulation and field measurement in order to explore the propagation law of underwater blasting water hammer waves and the influence of bubble curtain on the reduction effect of water hammer waves. The types of explosives and blasting parameters are studied by using different numerical simulation software, such as AUTODYN and ANSYS/LS-DYNA. It is concluded that the magnitude of the water hammer wave is related to the type of explosive in the case of the same amount of charge, TNT explosive $>$ high energy emulsion explosive $>$ ordinary emulsion explosive [9]. However, there are few research studies on the interval time of underwater millisecond blasting and the shape of air wall curtain. On the other hand, the attenuation effect of the air curtain on the peak value and impulse of the shock wave increases with the increase of the number of bubbles in the fixed air curtain area. However, when the number of bubbles in the air curtain area reaches a specific number, the attenuation rate tends to be stable [10]. It can be seen that the influence of the shape of the bubble curtain on the subsequent structure is also apparent. Consequently, based on the actual engineering background and the three-dimensional millisecond blasting model, which is more in line with the actual state, the influence of millisecond blasting interval on the propagation law of water hammer wave is studied. In addition, the reduction effect of bubble curtain on the water hammer wave in different positions is analyzed. This will help to solve the harmful effects of water hammer waves in practical engineering.

In the aspect of the propagation law of water hammer wave, Peng [11] derives the vibration frequency prediction formula considering the altitude effect. In addition, Ma et al. [12] analyze the peak velocity (PPV) of surface blasting of the same structure and predict the peak velocity of underwater blasting (PPV). Besides, Huang [13] establishes the numerical model of multimaterial arbitrary Lagrangian-Eulerian (MMALE) technique and studies the peak pressure of the explosive underwater explosion. Moreover, using the multiphase interface captured by the fluid volume (VOF) method, Liu [14] establishes the Eulerian finite element method (EFEM) for an underwater explosion. The underwater explosion at different depths is simulated, and the characteristics of near-field pressure are analyzed. Based on the finite element dynamic program LS-DYNA, according to the explosive rupture principle, Zhai [15] designs different explosive experimental conditions, the reserved hole parameters such as blasting parameters are designed, and the influence of stress wave is analyzed. Based on the blasting vibration data of underwater lighthouse from Ningbo to Shipu Port of Zhoushan Port, Gu [16] establishes a linear fitting model, and the vibration correction formula based on water depth is derived. Besides, Xin [17] monitors the underwater hammer wave through the first phase of the main channel project of Ningbo-Zhoushan Port Shipu Port. The characteristics of underwater hammer wave are obtained through the analysis of a typical measured pressuretime history curve. $\mathrm{Gu}$ [18] develops an underwater vibration monitor. The actual underwater vibration caused by underwater drilling blasting is measured and the vibration frequency band is analyzed with the help of this equipment. The above scholars have deduced the vibration prediction formula of water hammer wave, predicted the peak velocity, and studied the peak pressure of water hammer wave, the propagation characteristics of shock wave, and so on. However, there is no research on the propagation characteristics of water hammer waves based on different millisecond times.

In the aspect of the air curtain, Liu et al. [8] realize that a certain number of bubbles of different diameters were randomly placed in the set air curtain area to simulate the distribution of bubbles in the natural air curtain by programming with the APDL language of LS-DYNA finite element software during single-hole blasting. In addition, the air curtain effect under different pressure conditions was simulated by changing the number of air bubbles in the fixed area. Zhao et al. [9] carry out numerical simulation of underwater drilling and blasting with LS-DYNA software. Moreover, they study the propagation law of water hammer waves and the reduction effect of regular bubble curtain on water hammer waves. At present, many scholars mainly focus on the regular bubble wall and a small number of bubble combinations, but few on the real bubble wall.

The above researchers focused on single-hole blasting or fixed interval millisecond blasting. However, they did not systematically analyze the influence of millisecond blasting at a different time and using a real bubble curtain wall on the propagation law of water hammer wave. Combined with the specific engineering practice, how to determine the reasonable millisecond blasting time and the design of the actual bubble curtain wall, so that the adjacent structures behind the bubble curtain can be better protected, and ensure the safe operation of the project and improve the economic benefits of the project still needs to carry out indepth research work. As a consequence, this paper used the large-scale finite element simulation software ABAQUS to establish the three-dimensional model of underwater millisecond blasting based on the engineering background of cofferdam blasting at the inlet of Shibishan main canal tunnel in Ningguo City, Anhui Province, in view of the deficiency of the existing research. The concrete cutoff wall of cofferdam was simulated by ABAQUS built-in subroutine JH-2 (dynamic constitutive model with damage), and the blasting process is simulated by CEL, which is a coupling method of Eulerian and Lagrangian. Based on Python, a script was written to generate a three-dimensional real bubble curtain wall from large to small in the water depth 
direction by setting the maximum and minimum radius of bubbles and the difference interval between the minimum particle sizes. The study of millisecond time on the propagation law of water hammer wave caused by different water depths and bubble curtain was carried out to provide some reference for controlling the harmful effect of underwater blasting.

\section{Methodology}

3.1. Project Overview. The entrance of the Shibishan trunk canal diversion tunnel is located on the left bank upstream of Gangkouwan Reservoir in Ningguo City, Anhui Province, China, under the highway from Qinglong Township to Fangtang Town, X061 County Road. The surface below the highway is mainly abandoned residue during highway construction, and the topographic slope is about $35^{\circ}-40^{\circ}$. The excavation area and geological conditions of the project are shown in Figure 1. The side of the cofferdam cutoff wall is covered with slag filling and steel plate supporting structure. Besides, the blasting holes are arranged in a single row in the middle line of the concrete cutoff wall and detonated hole by hole. The excavated part and the gate chamber are all filled with water, so that the same water pressure is maintained inside and outside the cofferdam before blasting. The depth of the water level is about $20 \mathrm{~m}$, and the nearest distance between the intake building and the cofferdam is $20 \mathrm{~m}$, as shown in Figure 1.

3.2. Numerical Simulation Model. The underwater drilling and blasting model was established by coupling the Euler-Lagrange method aiming at the cofferdam structure of the entrance section of the Shibishan main canal tunnel. The numerical methods based on grid Eulerian body and the Lagrangian body cannot simulate the blasting process very well, so it is difficult to use these two methods. Coupled Lagrangian method (CEL) can separate the structure from the fluid, calculate the coupling on the contact surface, and solve the problems of mesh distortion. In the Lagrangian algorithm, the material is attached to the mesh, and the mesh will move and deform with the flow of the material. In the Eulerian algorithm, the mesh is fixed and does not move, while the material transfers between the meshes. Eulerian elements contain different substances, and the Eulerian volume fraction is used to describe the initial state and position of materials. The coupling algorithm completely separates the two kinds of calculation and transforms the material mesh into a fixed space mesh through the state variables of the Lagrange element, and the Lagrange body and Euler body are boundary conditions at the interface. In this numerical simulation, the Lagrange method solved the structure, and the fluid was solved by the Euler method. Two kinds of elements (Eulerian body and Lagrangian body) were included in the model. Water, air, and charge were modeled by the Eulerian body and the cofferdam and lock chamber were modeled by the Lagrangian body, both of which were divided by hexahedron mesh, and the contact was set as general contact. The calculation model is shown in Figure 2.
The calculation domain of the model was $30 \mathrm{~m} * 10 \mathrm{~m} * 30 \mathrm{~m}$, the water depth was $20 \mathrm{~m}$, the wall thickness was $0.8 \mathrm{~m}$, the pore diameter was $0.09 \mathrm{~m}$, the hole depth was $2 \mathrm{~m}$ according to the wall height removed, the minimum resistance line $\mathrm{W}$ was $0.4 \mathrm{~m}$, the distance between the holes was $0.8 \mathrm{~m}$, the plugging length was $0.8 \mathrm{~m}$, and the charge quantity per hole was $14 \mathrm{~kg}$. The nonreflection boundary condition was established to simulate the water boundary. The propagation laws of water hammer waves at different depths during prompt blasting and millisecond interval $10 \mathrm{~ms}, 20 \mathrm{~ms}, 30 \mathrm{~ms}$, and $40 \mathrm{~ms}$ blasting were studied, and the above five working conditions were studied under the condition that the charge was uncoupled and the total charge was constant.

The study of cylindrical charge by Hammond [19] shows that the shape of the charge has a significant influence on the shock wave performance of underwater explosion in a close range. The shock wave produced by the cylindrical charge can be approximated by a spherical charge with the same mass when the distance between the center of the explosion is more than half of the length of the charge. As a consequence, the cylindrical charge was equivalent to a regular spherical charge to simplify the calculation process.

3.3. Material Parameters. The equation of the state of the detonation products of the charge is based on the parameters of the JWL equation [20]. The equation of state is as follows:

$$
P=A\left(1-\frac{\omega \eta}{R_{1}}\right) e^{-\left(R_{1} / \eta\right)}+B\left(1-\frac{\omega \eta}{R_{2}}\right) e^{-\left(R_{2} / \eta\right)}+\omega \eta \rho_{0} e .
$$

In the formula, $\eta$ is the ratio of the detonation product density to the initial explosive density, that is, $\eta=\rho / \rho_{0}, A, B$, $R_{1}, R_{2}$, and $\omega$ are the constants related to the explosive state, and $e$ is the internal energy per unit mass of high explosives. The parameters are shown in Table 1.

By using ABAQUS built-in subroutine $\mathrm{JH} 2$ concrete material [21], the parameters are shown in Table 2.

The $U_{s}-U_{p}$ equation of state is used to simulate the water area, as shown in Table 3, and the equation of state is presented as follows:

$$
\begin{aligned}
P+P_{0} & =(\gamma-1) \rho E_{m}, \\
E_{m} & =c_{v}\left(\theta-\theta^{Z}\right) .
\end{aligned}
$$

In the formula, $P_{0}$ is the external pressure, $\gamma$ is the adiabatic index, $E_{m}$ is the internal energy per unit mass, $\rho$ is the density of air, $\theta$ is the current temperature, $\theta^{z}$ is absolute zero, and $c_{y}$ is the specific heat capacity.

The ideal gas (Ideal Gas) equation of state is used for air. The equation of state is as follows (Table 4):

$$
P=P_{H}\left(1-\frac{\Gamma_{0} \eta}{2}\right)+\Gamma_{0} \rho_{0} E_{m}
$$

In the formula, $E_{m}$ is the unit mass internal energy, $\Gamma_{0}$ is the material constant, $\rho_{0}$ is the reference density, Grü neisen ratio $\Gamma$ can be expressed as $\Gamma=\Gamma_{0}\left(\rho_{0} / \rho\right), \eta$ is the nominal 


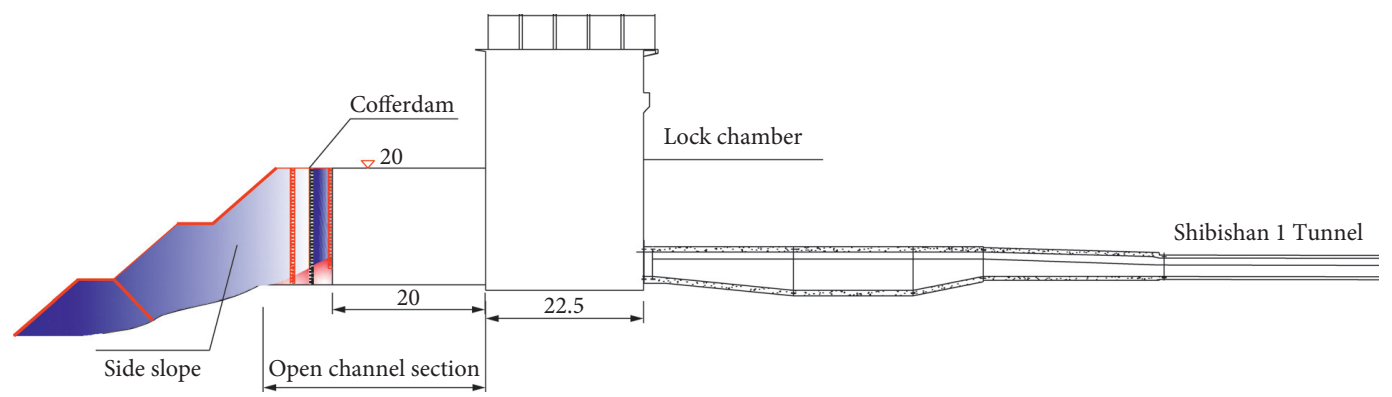

Figure 1: Project site map.

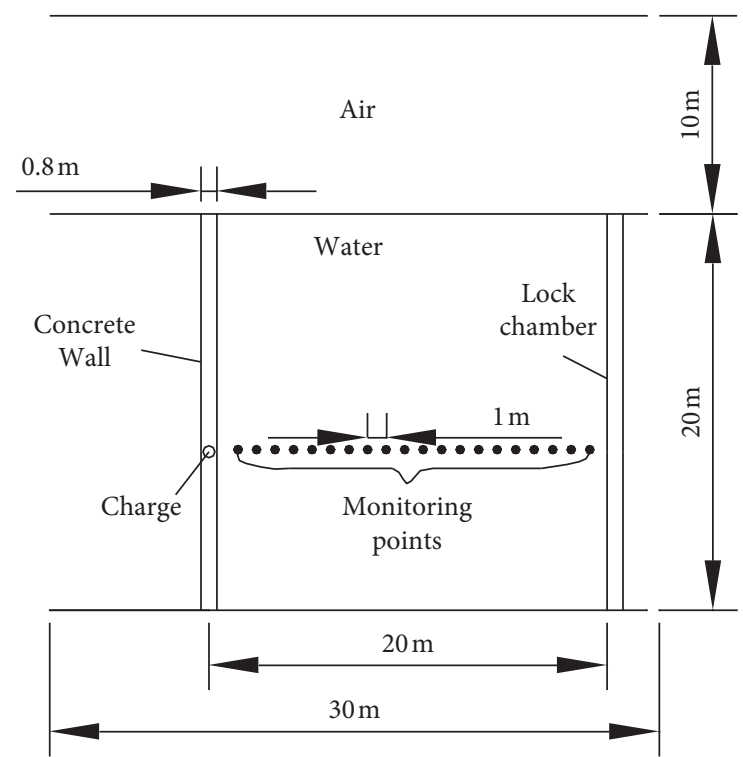

Figure 2: Schematic diagram of the calculation model.

volume compression strain, its expression is $\eta=1-\rho_{0} / \rho$, and $P_{H}$ is the Hugoniot pressure. By using the commonly used Hugoniot data, the expression is as follows:

$$
P_{H}=\frac{\rho_{0} c_{0}^{2} \eta}{(1-s \eta)^{2}}
$$

The linear equation of state in $U_{s}-U_{p}$ Hugoniot can be obtained as follows:

$$
P=\frac{\rho_{0} c_{0}^{2} \eta}{(1-s \eta)^{2}}\left(1-\frac{\Gamma_{0} \eta}{2}\right)+\Gamma_{0} \rho_{0} E_{m}
$$

In addition, $c_{0}$ and $s$ define linear impact velocity $U_{s}$ and particle velocity $U_{p}$ as follows:

$$
U_{S}=c_{0}+s U_{P} .
$$

The lock chamber adopts the ductile-damage failure criterion, and the parameters are shown in Table 5.

\section{Result Analysis and Discussion}

The propagation law of water hammer waves under different water depths with different millisecond times and the reduction effect of bubble curtain on water hammer wave at different positions were studied. The pressure cloud images of the water hammer wave in the explosion process are intercepted and analyzed. In addition, the typical unit was selected to extract the curve in the direction of the charge axis. Besides, the propagation law of the water hammer wave was analyzed at different water depths. In the meanwhile, the pressure-time history curve of the left and right measuring points of the bubble curtain was analyzed to quantify the reduction effect of the water hammer wave in different positions of the bubble curtain.

4.1. Pressure Nephogram. The charge adopts the uncoupled charge mode, which is equivalent to a regular sphere and is placed in the center of the borehole. The total time of wave propagation to the right boundary of a single charge explosion is $0.014 \mathrm{~s}$, the empirical propagation velocity of the wave in the solid is $6930 \mathrm{~m}$ shock s, and the propagation velocity in water is $1435 \mathrm{~m} / \mathrm{s}$. The explosion delay time of charge is $10 \mathrm{~ms}, 20 \mathrm{~ms}, 30 \mathrm{~ms}$, and $40 \mathrm{~ms}$ in order to study the propagation law of water hammer wave in different millisecond times. The total time of millisecond blasting is $0.04 \mathrm{~s}$, $0.06 \mathrm{~s}, 0.08 \mathrm{~s}$, and $0.1 \mathrm{~s}$ in order to ensure the integrity of wave propagation. Figure 3 shows the stress cloud diagram of water hammer waves at different times when delaying $10 \mathrm{~ms}$.

As shown in Figure 3(a), the first charge explodes first, and the water hammer wave caused by the explosion spreads in a spherical direction. As shown in Figure 3(b), the second charge explodes immediately after the first one in $12 \mathrm{~ms}$. As shown in Figure 3(c), the third charge explodes after the second one in $22 \mathrm{~ms}$. However, the water hammer wave pressure caused by the explosion of the first two charges reaches the third charge, and the water hammer waves caused by the explosion of the three charges influence each other. In addition, the pressure cloud diagram shows a "gourd" shape. As shown in Figure 3(d), the water hammer waves produced by the explosion of the three charges continue to spread outward in strips, and the stratification is evident after the water hammer waves are superimposed on each other.

\subsection{Propagation Law of Water Hammer Wave in Different} Millisecond Times. The pressure-time history curves of typical units at the distance of $3 \mathrm{~m}$ from prompt blasting and millisecond blasting (10 ms-40 ms) (unit number 54013) in the 
TABLE 1: JWL parameters for TNT charge.

\begin{tabular}{|c|c|c|c|c|c|c|c|}
\hline$\rho\left(\mathrm{kg} / \mathrm{m}^{3}\right)$ & $D(\mathrm{~m} / \mathrm{s})$ & $G_{1}(\mathrm{GPa})$ & $G_{2}(\mathrm{GPa})$ & $R_{1}$ & $R_{2}$ & $\omega$ & $e_{0}$ \\
\hline 1630 & 6930 & 373.8 & 3.747 & 4.15 & 0.9 & 0.35 & $6.0 \mathrm{e} 6$ \\
\hline
\end{tabular}

TABLE 2: JH2 parameters (Holmquist and Johnson 1993).

\begin{tabular}{lccccc}
\hline Variable & Numerical value & Variable & Numerical value & Variable & Numerical value \\
\hline$\rho\left(\mathrm{kg} / \mathrm{m}^{3}\right)$ & 2440 & $A$ & 0.79 & $c$ & 0.007 \\
$G(\mathrm{GPa})$ & 14.86 & $B$ & 1.6 & $\varepsilon_{f m a x}$ & 0.61 \\
$\varepsilon_{0}$ & 1 & $T(\mathrm{GPa})$ & 0.00354 & 0.001 & $P_{\text {hel }}(\mathrm{MPa})$ \\
$S_{\max }$ & 7 & $\varepsilon_{\text {fmin }}$ & 85 & $K_{3}(\mathrm{GPa})$ & 48 \\
$D_{1}$ & 0.04 & $K_{1}(\mathrm{GPa})$ & -171 & $H E L$ & 208 \\
$D_{2}$ & 1 & $K_{2}(\mathrm{GPa})$ & & & 80 \\
\hline
\end{tabular}

TABLE 3: Water model and state equation parameters.

\begin{tabular}{lcccc}
\hline$\rho\left(\mathrm{kg} / \mathrm{m}^{3}\right)$ & $\mathrm{c} 0$ & $\mathrm{~s}$ & $\Gamma$ & Viscosity \\
\hline 983 & 1435 & 1.75 & 0.28 & 0.00094 \\
\hline
\end{tabular}

TABle 4: Air model and state equation parameters.

\begin{tabular}{lcccc}
\hline $\begin{array}{l}\rho(\mathrm{kg} / \\
\left.\mathrm{m}^{3}\right)\end{array}$ & $\begin{array}{c}\text { Gas } \\
\text { constant }\end{array}$ & $\begin{array}{c}\text { Ambient pressure } \\
(\mathrm{Pa})\end{array}$ & $\begin{array}{c}\text { Specific } \\
\text { heat }\end{array}$ & Viscosity \\
\hline 1.2 & 287 & 101325 & 717.7 & $8.25 e-5$ \\
\hline
\end{tabular}

direction of the minimum resistance line of charge were extracted under the condition that the total charge quantity was constant in order to quantitatively study the pressure attenuation law of water hammer wave with different millisecond times, as shown in Figure 4.

Figure 4 shows the pressure-time history curve at $3 \mathrm{~m}$ in the direction of the axis of the blasting charge with different millisecond times. It can be seen that the attenuation trend of the curve of different millisecond times is similar. It will produce enormous energy in a concise when the charge begins to detonate. It is characterized by the rapid rise of the water hammer wave curve. Because the propagation velocity of the seismic wave is more significant than that of the water hammer wave, there is a precursor wave in the pressure-time history curve [8]. There are multiple peaks in the peak pressure curve of the water hammer wave at the typical unit in the case of different millisecond times, which was caused by the successive explosion of the charge. The stress waves of the three charge delay explosions cancel each other. The vibration waves and the central frequency generated by each blast hole are staggered with each other. Each segment reaches the peak value independently and then decays. The second peak pressure is higher and the third peak pressure is significantly lower in the image.

A typical unit with a distance of one meter from $r$ was taken in the direction of the minimum resistance line of the intermediate charge in order to further study the attenuation law of the water hammer wave, and the monitoring point is shown in Figure 2. The variation of the peak pressure of the typical unit with the explosion center distance is extracted in the case of each millisecond time, as shown in Figure 5.

As shown in Figure 5, the peak pressure of the water hammer wave shows an exponential attenuation trend with the increase of the explosion center distance in the direction of the minimum line of resistance. In the range of explosion center distance from $1 \mathrm{~m}$ to $5 \mathrm{~m}$, the attenuation of the water hammer wave is the most obvious. Besides, the attenuation velocity of the water hammer wave is different in different millisecond times.

At the same distance from the charge, the peak pressure of the water hammer wave is different in different millisecond times in the direction of the center of the charge. The peak pressure of the water hammer wave is $86 \mathrm{MPa}$ at millisecond interval $10 \mathrm{~ms}, 85 \mathrm{MPa}$ at millisecond interval $20 \mathrm{~ms}, 74 \mathrm{MPa}$ at millisecond interval $30 \mathrm{~ms}$, and $80 \mathrm{MPa}$ at millisecond interval $40 \mathrm{~ms}$. It can be concluded that the peak pressure of the water hammer wave is the lowest at millisecond interval $30 \mathrm{~ms}$.

Cole proposed that the attenuation formula of the water hammer wave is presented as follows:

$$
p=a\left(\frac{\sqrt[3]{Q}}{r}\right)^{b}
$$

In the formula, $p$ is the pressure of the water hammer wave, $Q$ is the amount of charge in a single hole, $Q=14 \mathrm{~kg}$, and $r$ is the distance between the explosion source and the measuring point.

Based on equation (7), the peak pressure of the water hammer wave is fitted by nonlinear exponential fitting, and the fitting curve is shown in Figure 6.

The fitting parameter $a=16.43, b=1.09$, and $s=0.98$. $s$ is the relevant parameter of fitting, the nearer $s$ is, the better the fitting effect is in the case of prompt blasting. The attenuation formula of water hammer wave in prompt blasting is as follows:

$$
p=16.43\left(\frac{\sqrt[3]{Q}}{r}\right)^{1.09}
$$

The $a, b$, and $s$ parameters of delay $10 \mathrm{~ms}, 20 \mathrm{~ms}, 30 \mathrm{~ms}$, and $40 \mathrm{~ms}$ are shown in Table 6 .

It can be obtained from Table 6 that the fitting parameter $a$ fluctuates slightly, the $b$ value changes little, and the fitting effect is better when blasting with different millisecond times. The relevant results can provide a reference for predicting the peak attenuation of water hammer pressure under similar working conditions. At the millisecond interval of $0 \mathrm{~ms}$, the peak 
TABLE 5: Steel parameters.

\begin{tabular}{lcccc}
\hline$\rho(\mathrm{kg} / \mathrm{m} 3)$ & Young's modulus $(\mathrm{GPa})$ & Poissonby & \multicolumn{2}{c}{ Ductile damage } \\
\hline 7800 & 206 & 0.2 & 2.193828 & 0 \\
& & & 0.314962024 & Stress triaxiality \\
\hline
\end{tabular}
(Avg: $100 \%)$

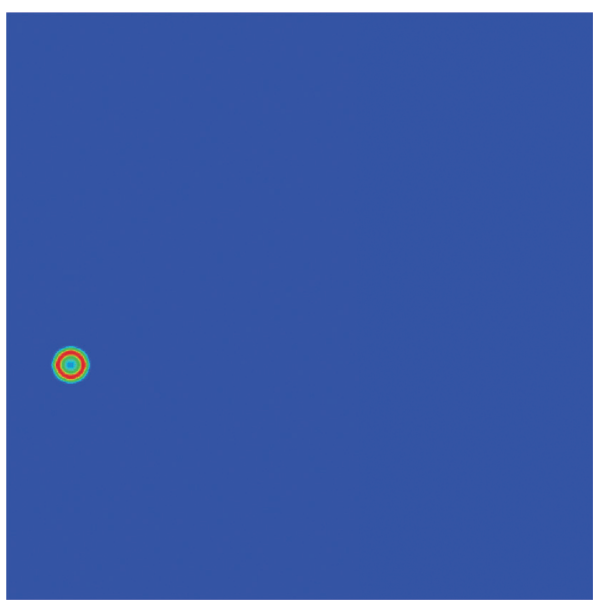

(a)
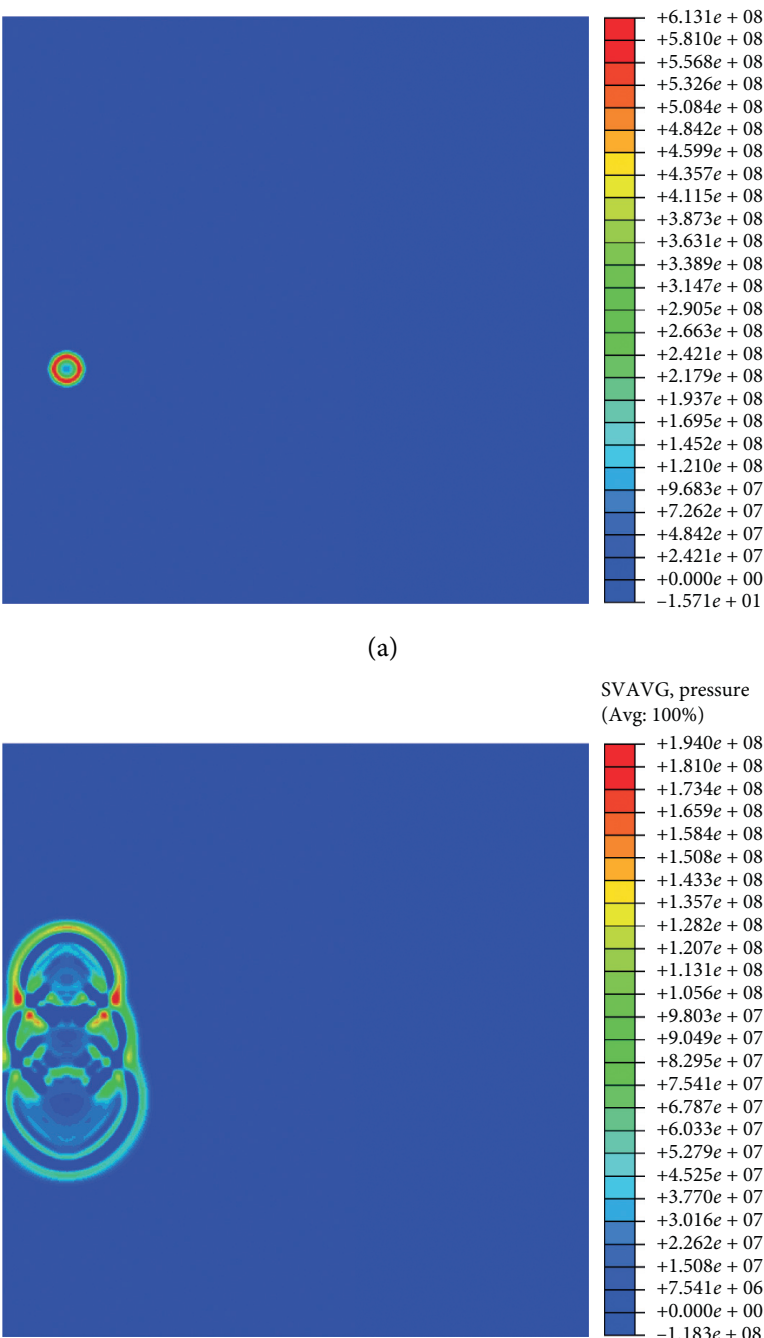

(c)

SVAVG, pressure (Avg: 100\%)

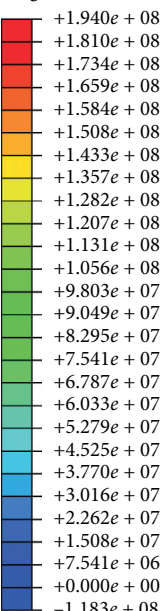

$+0.000 e+00$

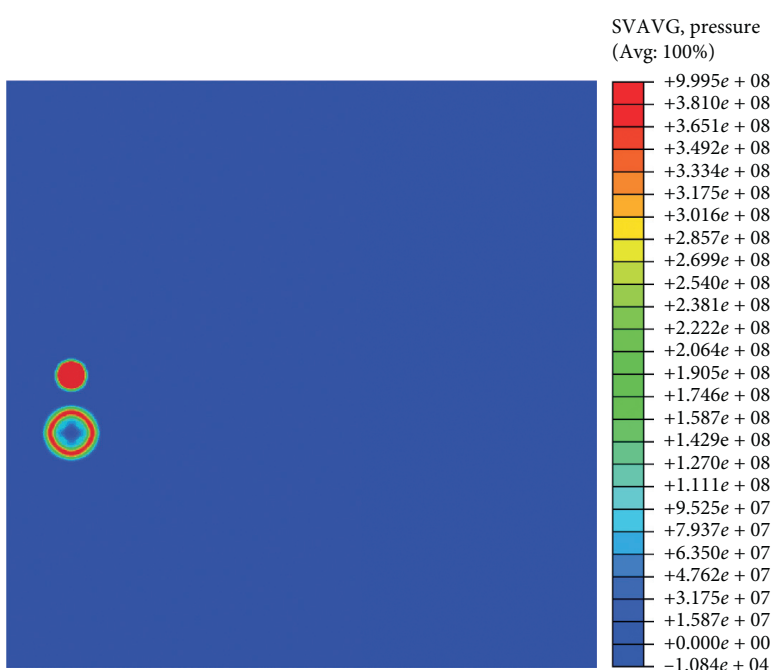

(b)

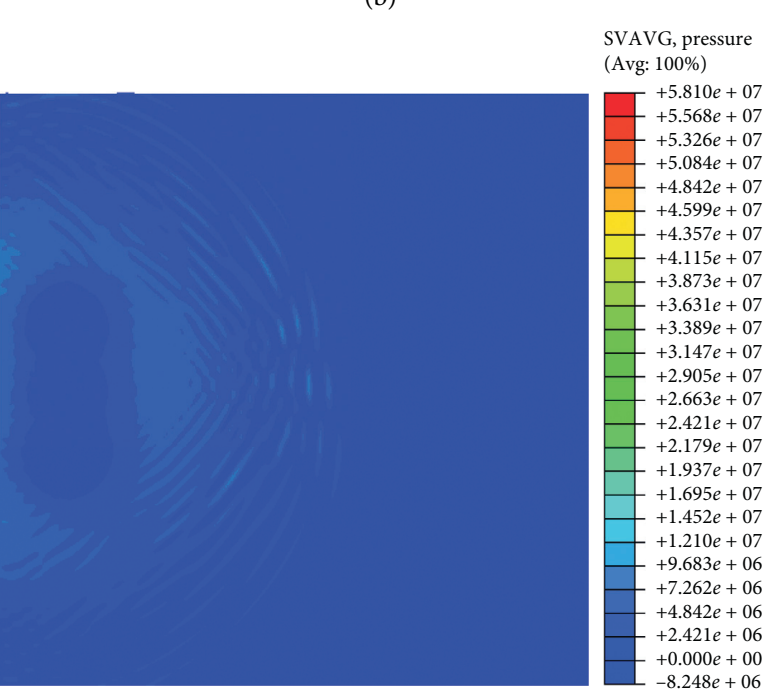

(d)

Figure 3: Stress nephogram of $10 \mathrm{~ms}$ delayed SVAG pressure. (a) $8 \mathrm{~ms}$. (b) $12 \mathrm{~ms}$. (c) $22 \mathrm{~ms}$. (d) $25 \mathrm{~ms}$.

pressure of the water hammer wave attenuates from $90 \mathrm{MPa}$ to 4.5 $\mathrm{MPa}$, by $95.0 \%$. At the millisecond interval $10 \mathrm{~ms}$, the peak pressure attenuates from $86 \mathrm{MPa}$ to $2.1 \mathrm{MPa}$, which is $95.2 \%$ lower. At millisecond interval $20 \mathrm{~ms}$, the peak pressure attenuates from $85 \mathrm{MPa}$ to $2.5 \mathrm{MPa}$, decreasing by $97.1 \%$. At the millisecond interval of $30 \mathrm{~ms}$, the peak pressure attenuates from $74 \mathrm{MPa}$ to $1.8 \mathrm{MPa}$, which decreases by $97.6 \%$. At the millisecond interval of $40 \mathrm{~ms}$, the peak pressure attenuates from
$80 \mathrm{MPa}$ to $2.2 \mathrm{MPa}$, an attenuation of $97.2 \%$. Peak pressure attenuation is shown in Figure 7.

With the increase of millisecond time, the attenuation velocity of peak pressure of water hammer wave increases first and then decreases. It can be concluded that the attenuation rate of peak pressure of water hammer wave was the fastest and the peak pressure of water hammer wave was the smallest in the case of millisecond interval $30 \mathrm{~ms}$ through 


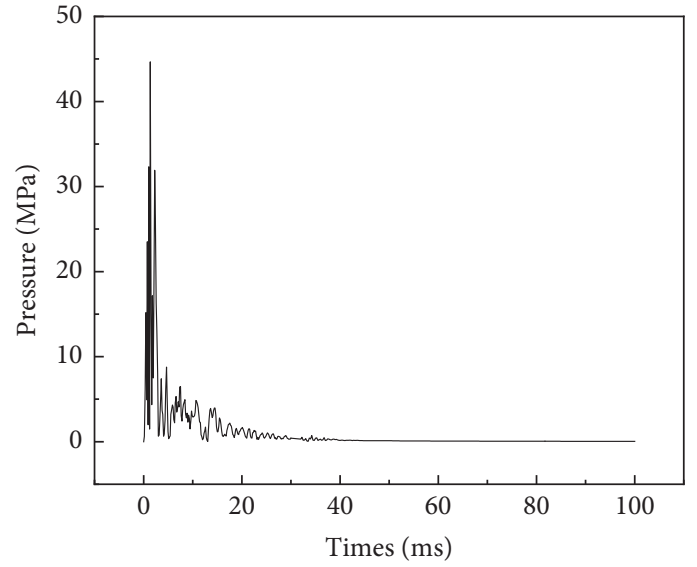

— Delay $0 \mathrm{~ms}$

(a)

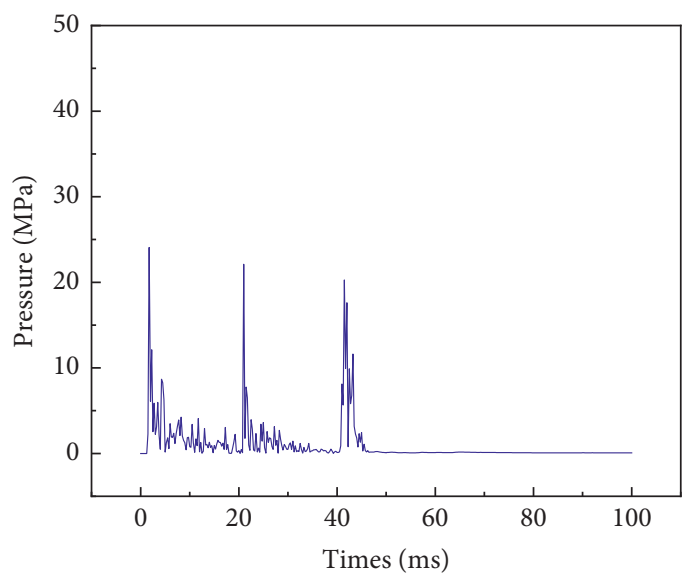

— Delay $20 \mathrm{~ms}$

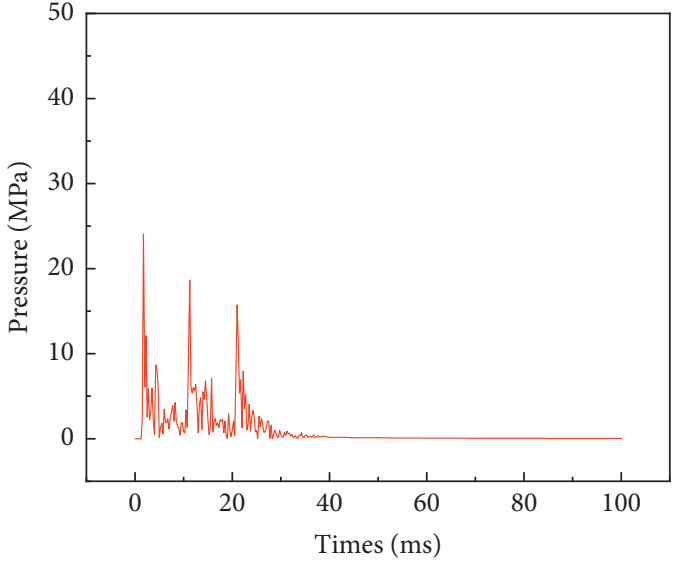

— Delay $10 \mathrm{~ms}$

(b)

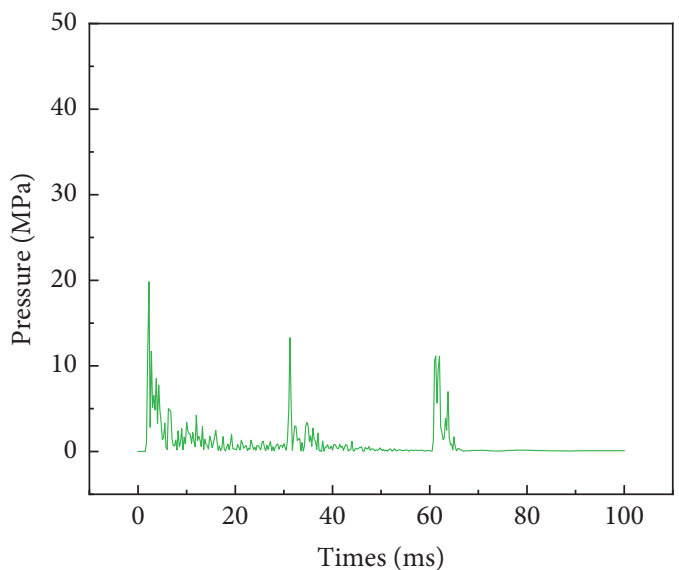

— Delay $30 \mathrm{~ms}$

(c)

(d)

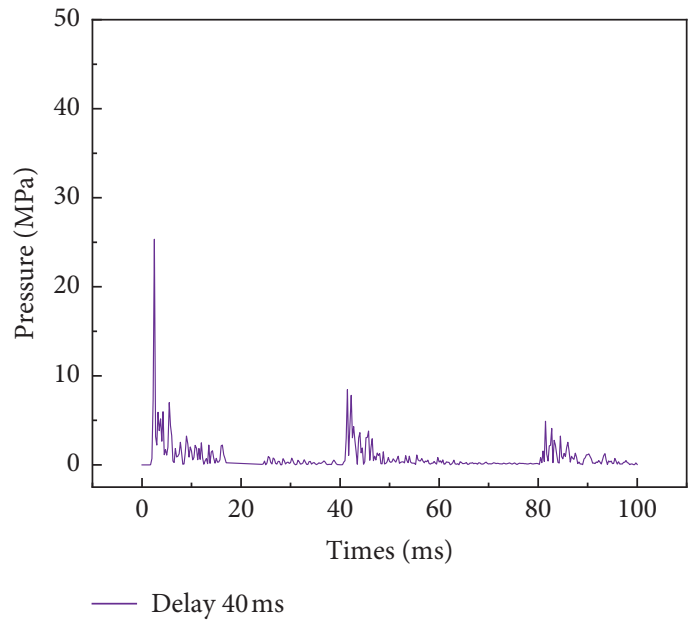

(e)

Figure 4: Typical unit pressure-time history curve. (a) Delay 0 ms. (b) Delay 10 ms. (c) Delay 20 ms. (d) Delay 30 ms. (e) Delay 40 ms. 


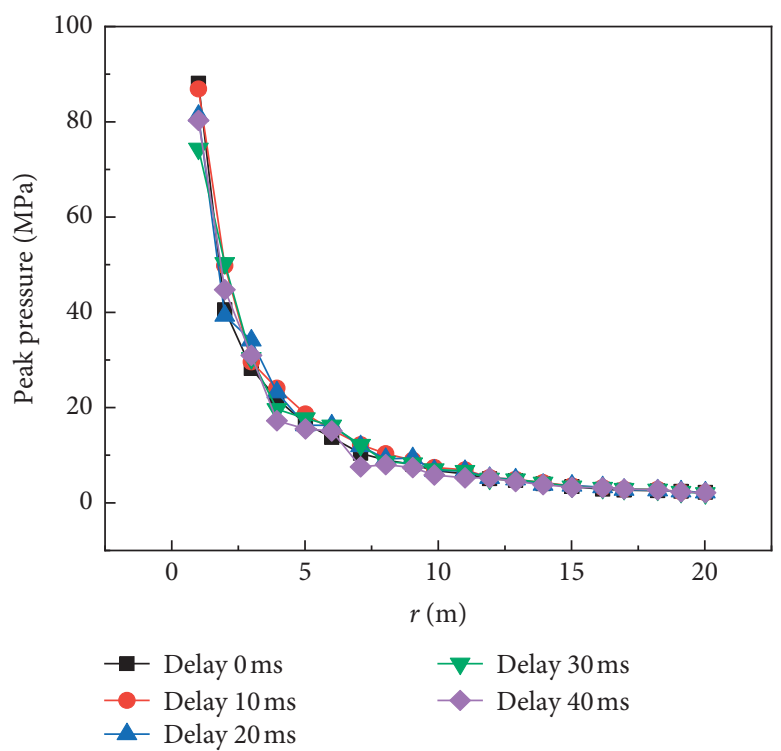

Figure 5: The change of the peak pressure in the direction of the minimum resistance line with the burst center distance.

the analysis of the propagation law of water hammer wave with different millisecond times.

\subsection{Influence ofDifferent Millisecond Times and Water Depths} on Propagation Law of Water Hammer Wave. The attenuation velocity of water hammer waves in different water depths is different. The curve of the peak pressure along the direction of the minimum line of resistance with the center of the explosion at the water depth of $5 \mathrm{~m}$ and $20 \mathrm{~m}$ was extracted in order to study the influence of different millisecond times on the pressure propagation law of the water hammer wave at different water depths, as shown in Figure 8.

As shown in Figure 8, the peak pressure attenuation with the explosion center distance also attenuates exponentially in different water depths. In addition, the peak pressure of the water hammer wave is the highest when the $0 \mathrm{~ms}$ is delayed. The peak pressure of the water hammer wave is 12.0 $\mathrm{MPa}$ at the depth of $5 \mathrm{~m}$ and $4.9 \mathrm{MPa}$ at the depth of $20 \mathrm{~m}$.

As shown in Figure 8(a), the peak pressure of the water hammer wave attenuates from $12.0 \mathrm{MPa}$ to $2.7 \mathrm{MPa}$, attenuating by $77.5 \%$, and the peak pressure of the water hammer attenuates from $8.12 \mathrm{MPa}$ to $1.8 \mathrm{MPa}$, attenuating by $77.8 \%$ when millisecond blasting is $0 \mathrm{~ms}$ and millisecond blasting is $10 \mathrm{~ms}$. When millisecond blasting is $20 \mathrm{~ms}$, the peak pressure of water hammer attenuates from $8.02 \mathrm{MPa}$ to 1.7 $\mathrm{MPa}$, by $78.9 \%$. When millisecond blasting is $30 \mathrm{~ms}$, the peak pressure of water hammer attenuates from $7.56 \mathrm{MPa}$ to 1.4 MPa, by $81.4 \%$. When millisecond blasting is $40 \mathrm{~ms}$, the peak pressure of water hammer attenuates from $7.78 \mathrm{MPa}$ to 1.7 $\mathrm{MPa}$, attenuating by $78.1 \%$.

As shown in Figure 8(b), when millisecond blasting is $0 \mathrm{~ms}$, the peak pressure of water hammer wave decays from 4.9 $\mathrm{MPa}$ to $1.2 \mathrm{MPa}$, and the attenuation rate is $75.5 \%$. The peak pressure of the water hammer decreases from $3.96 \mathrm{MPa}$ to $0.95 \mathrm{MPa}$, which is $76.0 \%$ when the millisecond blasting is
$10 \mathrm{~ms}$. The peak pressure of the water hammer decreased from $3.63 \mathrm{MPa}$ to $0.82 \mathrm{MPa}, 77.4 \%$, when millisecond blasting was $20 \mathrm{~ms}$. The peak pressure of the water hammer decreased from $3.38 \mathrm{MPa}$ to $0.8 \mathrm{MPa}$, which decreased by $79.1 \%$, when the millisecond blasting time was $30 \mathrm{~ms}$. When the millisecond blasting time is $40 \mathrm{~ms}$, the peak pressure of the water hammer decreases from $3.49 \mathrm{MPa}$ to $0.9 \mathrm{MPa}$, which is $74.2 \%$. It can be seen that the peak pressure of the water hammer wave in millisecond blasting $30 \mathrm{~ms}$ was the smallest and the attenuation was the fastest. In addition, when the water depth was changed, this conclusion was still valid. The attenuation velocity of the water hammer wave was different in different water depths. The attenuation velocity of the water hammer wave increased at first and then decreased with the increase of water depth. The peak pressure of the water hammer wave was the highest and the attenuation speed was the fastest at the water depth of $10 \mathrm{~m}$.

\subsection{Reducing Effect of Bubble Curtain Wall on Water Hammer} Wave. Measures need to be taken to buffer the water hammer wave to ensure the safety of the lock chamber and further reduce the impact of the water hammer wave. The bubble curtain wall is a new method to reduce the shock wave of underwater blasting, which has been widely used because of its good effect of blocking water hammer wave [1].

Python generated the bubble curtain generated by random bubbles based on the maximum and minimum radius and the minimum interparticle radius to simulate the real bubble curtain wall. In addition, the peak value of the water hammer wave before and after the bubble curtain was studied, which provides a sure basis for protecting the safety of adjacent structures. The schematic diagram of the model is shown in Figure 9. The stress nephogram is shown in Figure 10.

Figure 10 is a schematic diagram of the stress of water hammer wave weakened by bubble curtain during $30 \mathrm{~ms}$ millisecond blasting. It can be seen that the bubble curtain 


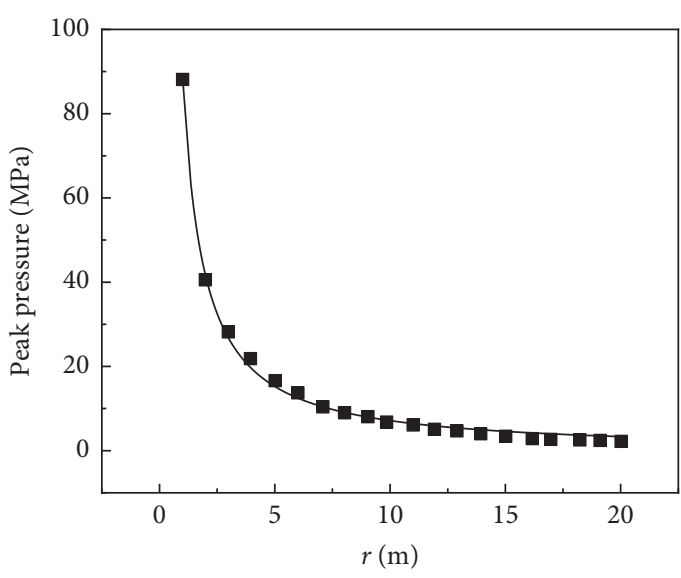

- Delay $0 \mathrm{~ms}$

_ Curve fitting

(a)

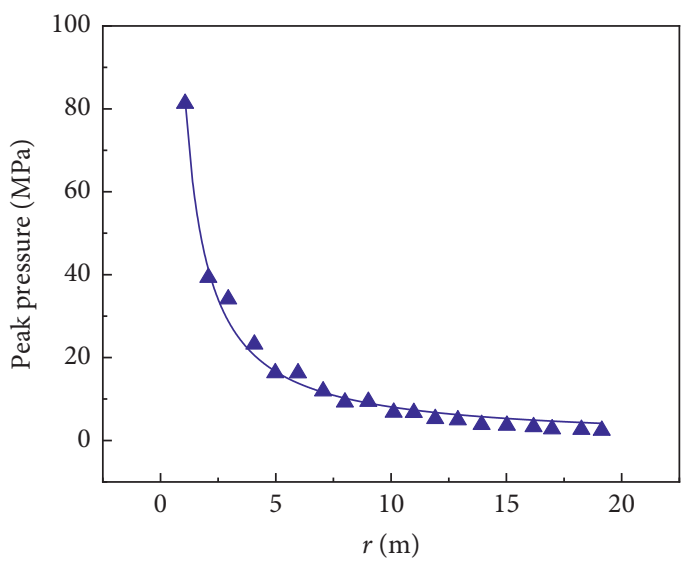

- Delay $20 \mathrm{~ms}$

- Curve fitting

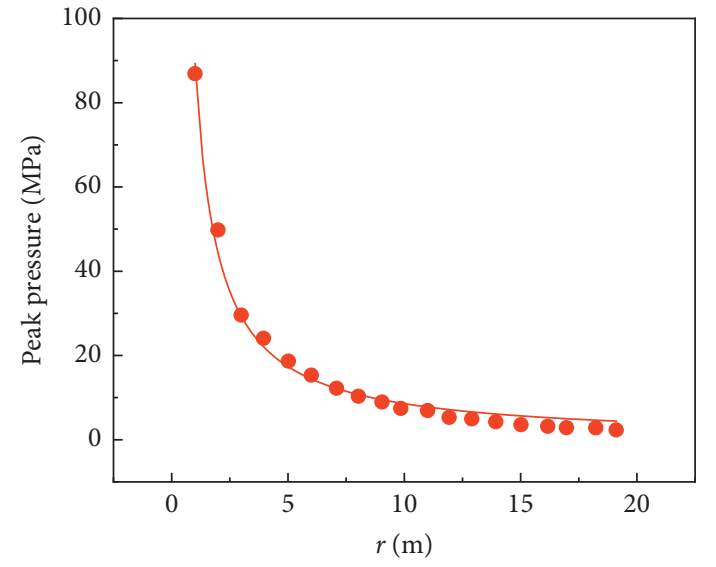

- Delay $10 \mathrm{~ms}$

_ Curve fitting

(b)

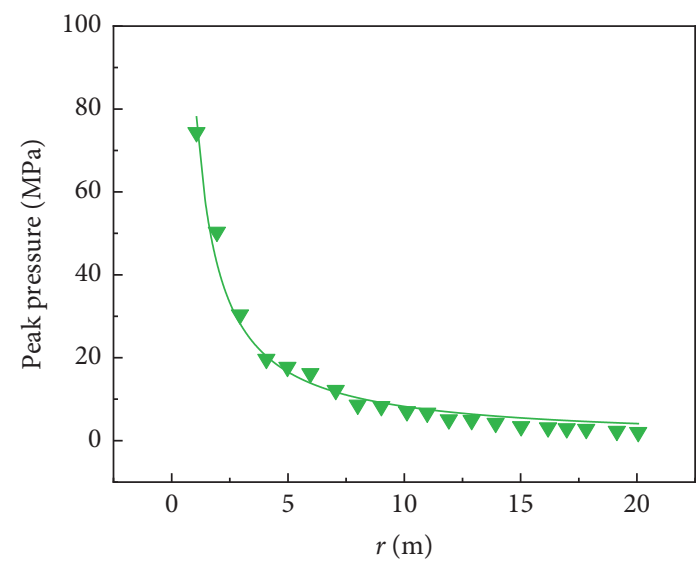

$\nabla$ Delay $30 \mathrm{~ms}$

— Curve fitting

(c)

(d)

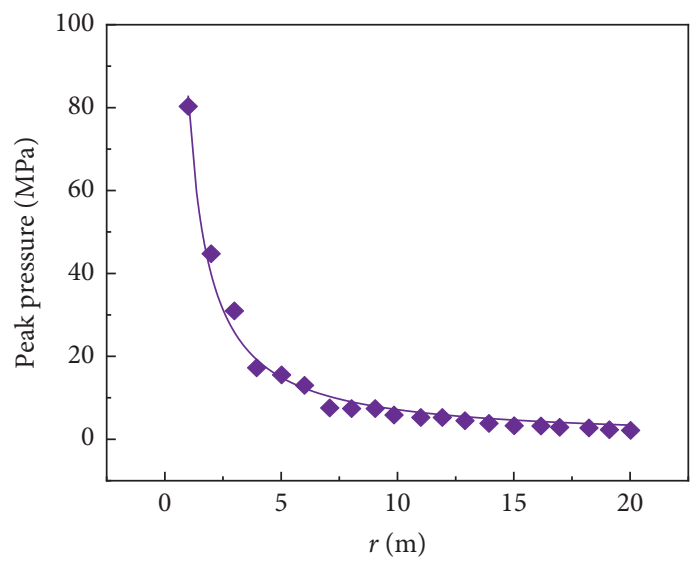

- Delay $40 \mathrm{~ms}$

Curve fitting

(e)

Figure 6: The attenuation curve of water hammer wave on the minimum resistance line. (a) Delay 0 ms fitting curve. (b) Delay 10 ms hole blasting fitting curve. (c) Delay $20 \mathrm{~ms}$ fitting curve. (d) Delay $30 \mathrm{~ms}$ hole blasting fitting curve. (e) Delay $40 \mathrm{~ms}$ hole blasting fitting curve. 
TABLE 6: Fitting parameters.

\begin{tabular}{lccr}
\hline Delay time $(\mathrm{ms})$ & $a$ & $b$ & $s$ \\
\hline 0 & 16.43 & 1.09 & 0.98 \\
10 & 18.55 & 1.02 & 0.90 \\
20 & 17.76 & 1.03 & 0.95 \\
30 & 17.76 & 1.00 & 0.97 \\
40 & 16.38 & 1.05 & 0.98 \\
\hline
\end{tabular}

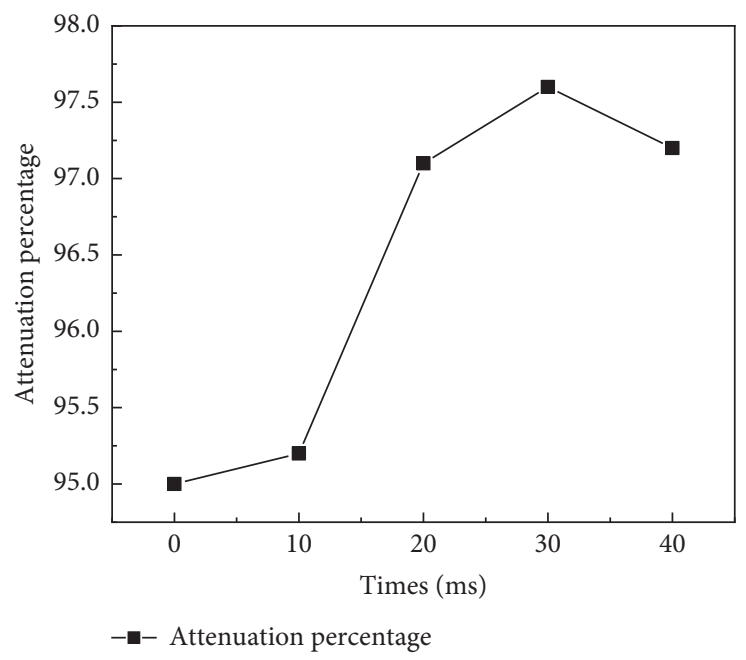

Figure 7: Attenuation ratio of peak pressure at $10 \mathrm{~m}$ water depth.

wall has a good effect on reducing the water hammer wave. When the water hammer wave passes through the bubble curtain wall, the peak pressure of the water hammer wave is significantly weakened behind the wall due to the refraction and reflection of the air in the bubble and the diffuse reflection of the bubble surface. As shown in Figure 10(a), the charge explodes in the concrete wall quickly, forming a circular water hammer wave. The water hammer wave continues to propagate to the bubble curtain. As shown in Figure 10(b), the water hammer wave is flattened near one end of the bubble curtain, which is due to the difference between the left and correct medium impedance of the bubble curtain. In $8 \mathrm{~ms}$, when the water hammer wave is transferred to the bubble curtain wall, cavitation will occur near the free surface where the air and water contact, which shows that the pressure of water hammer wave in the cavitation area behind the wall decreases, the difference between the water hammer pressure and the far away from water hammer pressure in cavitation area is not significant, as shown in Figure 10(c), most of the incident waves are reflected by the bubble curtain, and the reflected water hammer waves propagate to the concrete impervious wall. The secondary reflected incident waves continue to propagate along the direction of the bubble curtain. The superimposed coincidence of the light waves reflects several times propagates to the bubble curtain. In addition, the sparse incident waves continue to diverge outward through the gap between the bubble curtains, as shown in Figure 10(d).
The measuring points were set up on the explosion face and back explosion surface of the bubble curtain in order to quantitatively study the reduction effect of the water hammer wave, centering on the position elevation of the charge (the face mark of the forward explosion is 1 and that of the back explosion is 2). The pressure-time history curves of the measuring points on the left and right sides of the bubble curtain at the distance of $3 \mathrm{~m}$, $5 \mathrm{~m}, 8 \mathrm{~m}, 10 \mathrm{~m}$, and $15 \mathrm{~m}$ from the charge are extracted, respectively, the pressure-time history curves of each measuring point are shown in Figure 11, and the peak pressure of each point is shown in Table 7.

As shown in Figure 11, with the increase of the distance between the bubble curtain and the charge, the effect of water hammer wave reduction becomes worse and worse. The percentage reduction is shown in Table 7.

Figure 12 shows the attenuation effect of bubble curtain at different distances from the charge.

As shown in Figure 12 and Table 7, the pressure-time history curves are $15 \mathrm{~m}, 10 \mathrm{~m}, 8 \mathrm{~m}, 5 \mathrm{~m}$, and $3 \mathrm{~m}$ away from the center of the charge, respectively. Figure 11 shows the attenuation percentage curve at different distances from the bubble curtain to the charge. It can be seen from Table 7 that when the bubble curtain is $15 \mathrm{~m}$ away from the center of the charge, the peak pressure attenuates by $75.0 \%$. When the distance is $10 \mathrm{~m}$, the peak pressure attenuates by $80.0 \%$, when the distance is $8 \mathrm{~m}$ from the center of the charge, the attenuation of the peak pressure is $82.3 \%$, when the distance is $5 \mathrm{~m}$, the peak 


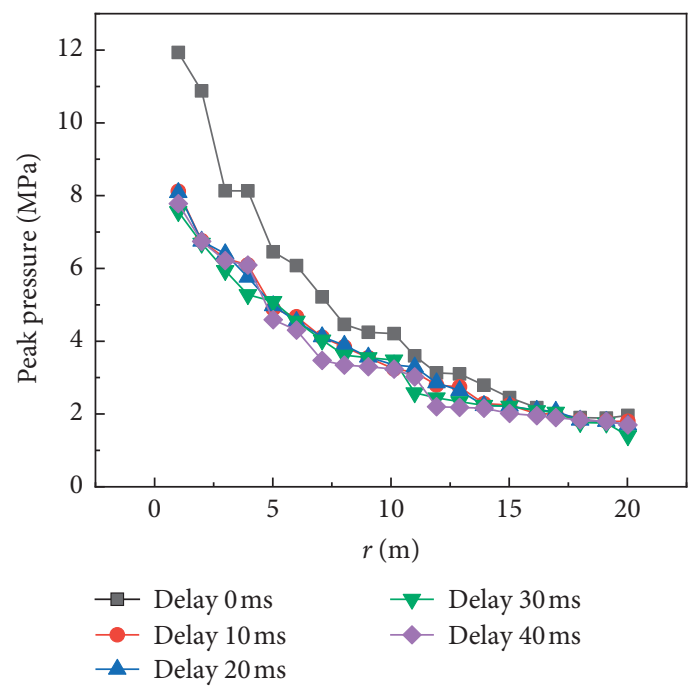

(a)

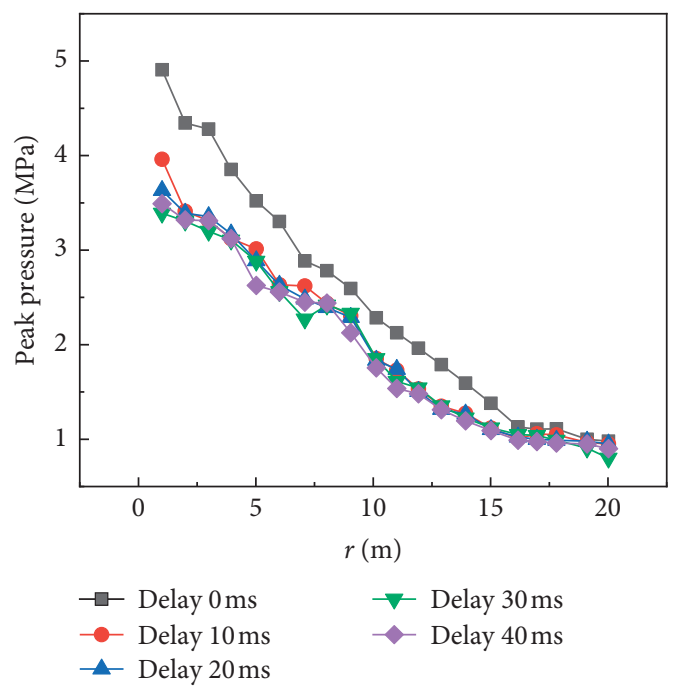

(b)

Figure 8: The attenuation curve of water hammer wave on the minimum resistance line. (a) $5 \mathrm{~m}$. (b) $20 \mathrm{~m}$.

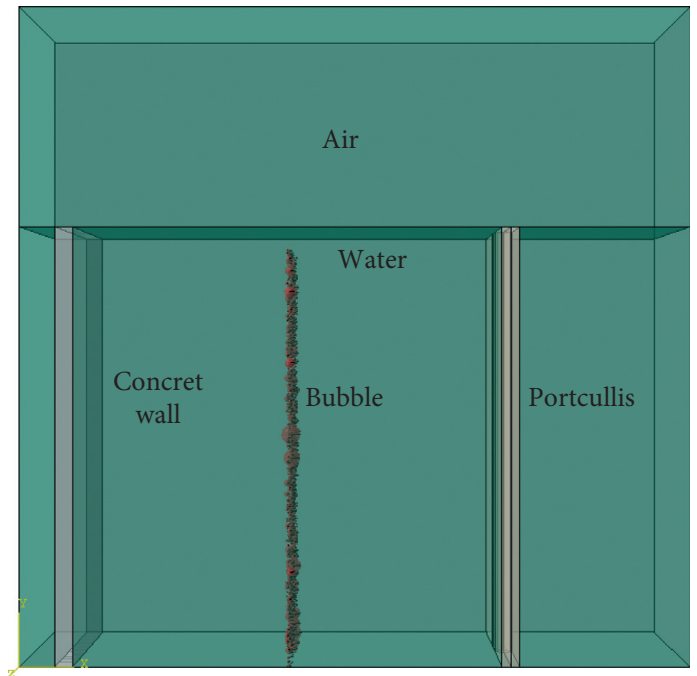

Figure 9: Schematic diagram of numerical simulation.

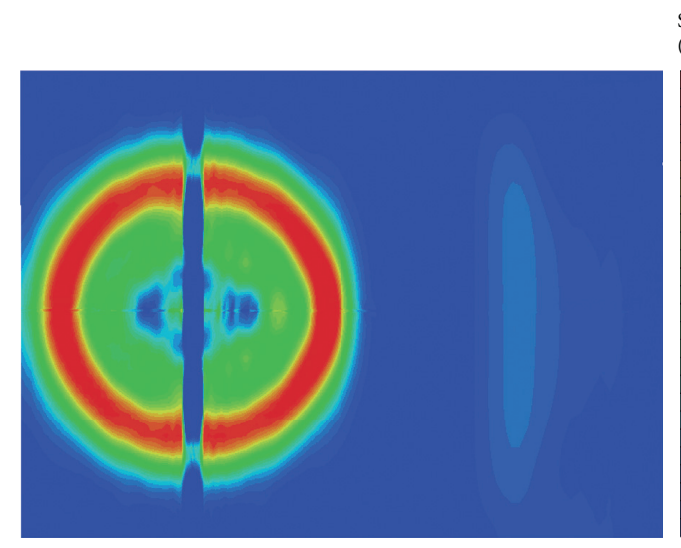

(a)
SVAVG, pressure

(Avg: $100 \%$ )

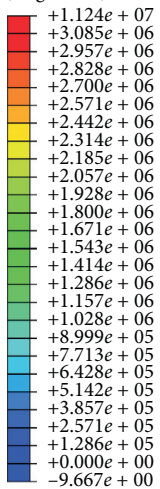

$+0.000 e+00$
$-9.667 e+00$

FIgUre 10: Continued.
SVAVG, pressure (Avg: 100\%)

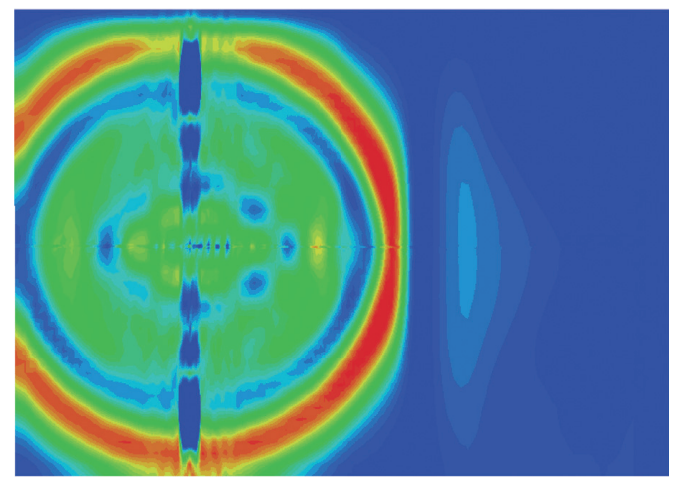

(b)

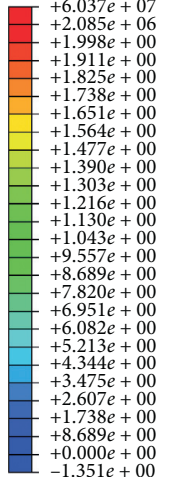

$+0.000 e+00$
$-1.351 e+00$ 
SVAVG, pressure (Avg: 100\%)

SVAVG, pressure

$+1.254 e+07$

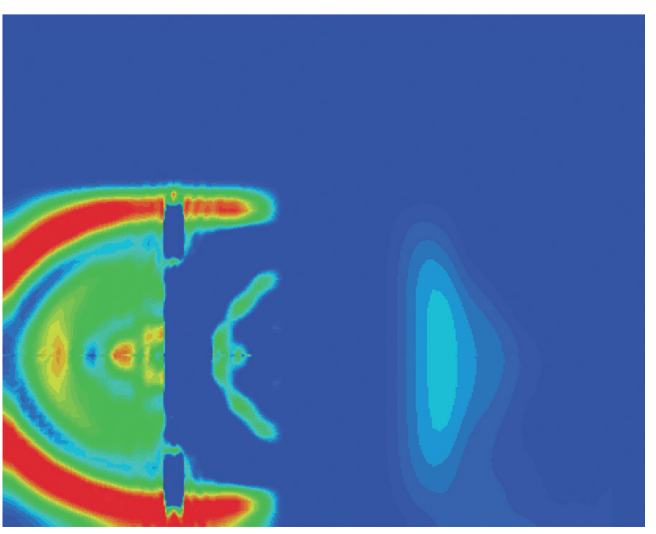

(c)

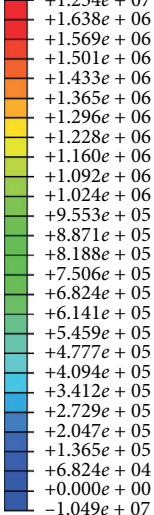

$+0.000 e+00$
$-1.049 e+07$
(Avg: $100 \%$ )

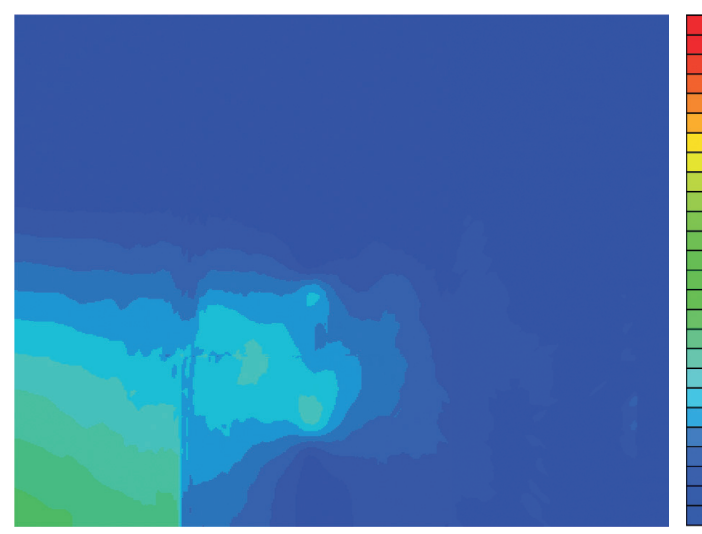

$7.011 e+05$

$+4.933 e+05$

$+4.698 e+05$

$+4.463 e+05$

$+4.228 e+05$

(

$+3.758 e+05$

3.054e+05

$+2.584 e+05$

$+2.349 e+05$

$+1.879 e+05$

$+1.644 e+05$

$+1.409 e+05$

$+1.175 e+05$

$+7.047 e+04$

$+2.349 e+0$

$+0.000 e+00$
$-1.113 e+06$

(d)

Figure 10: Stress nephogram of bubble wall weakening water hammer wave. (a) $0.05 \mathrm{~ms}$. (b) $4 \mathrm{~ms}$. (c) $8 \mathrm{~ms}$. (d) $20 \mathrm{~ms}$.
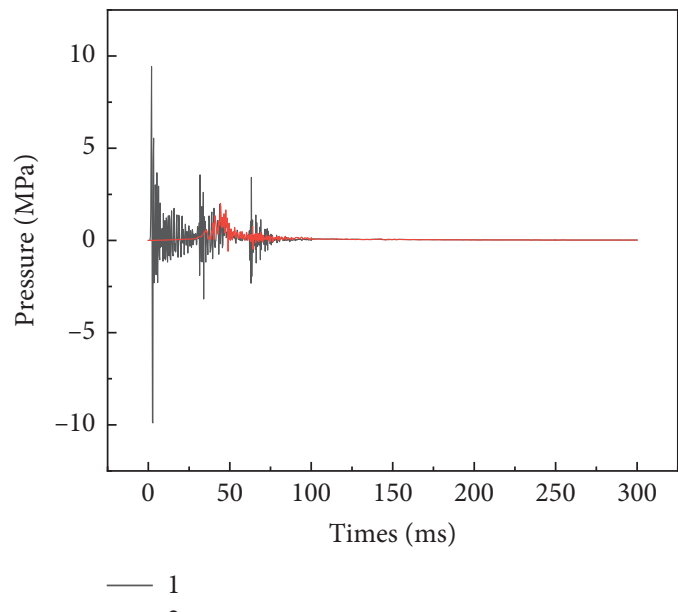

(a)

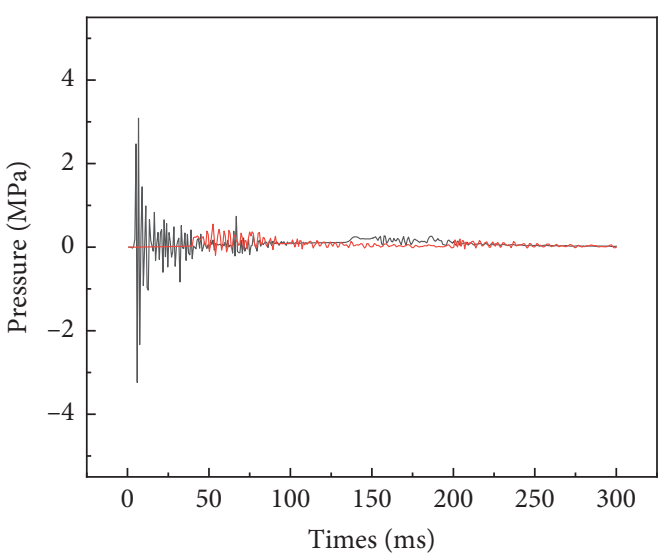

$-1$

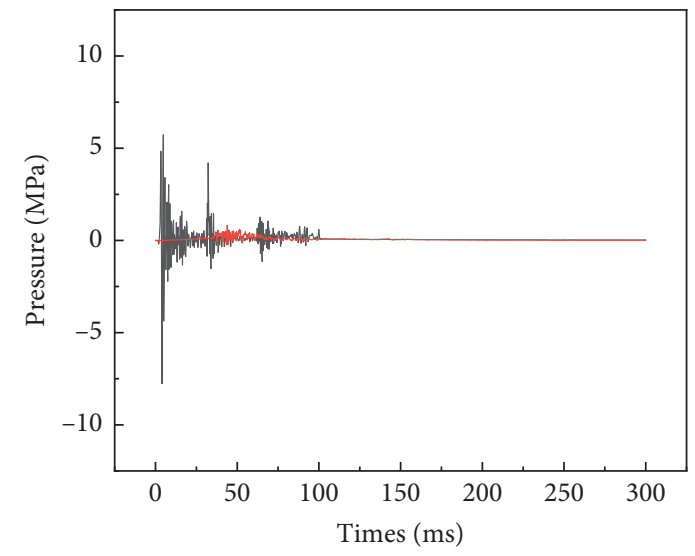

$-1$

(b)

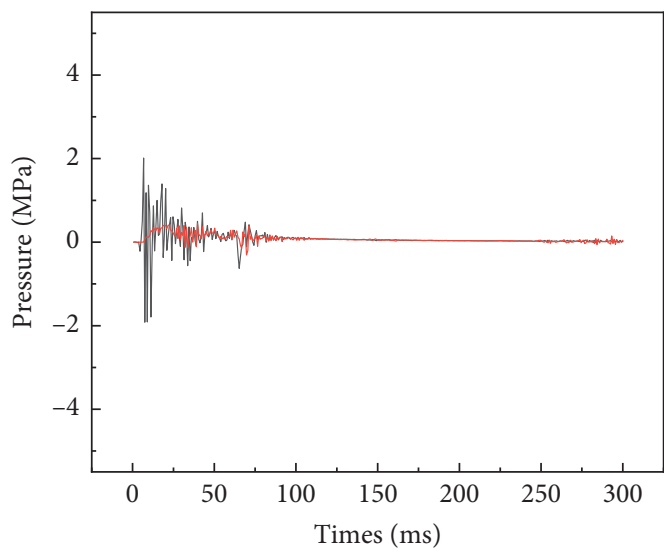

- 1

(c)

FIgURE 11: Continued. 


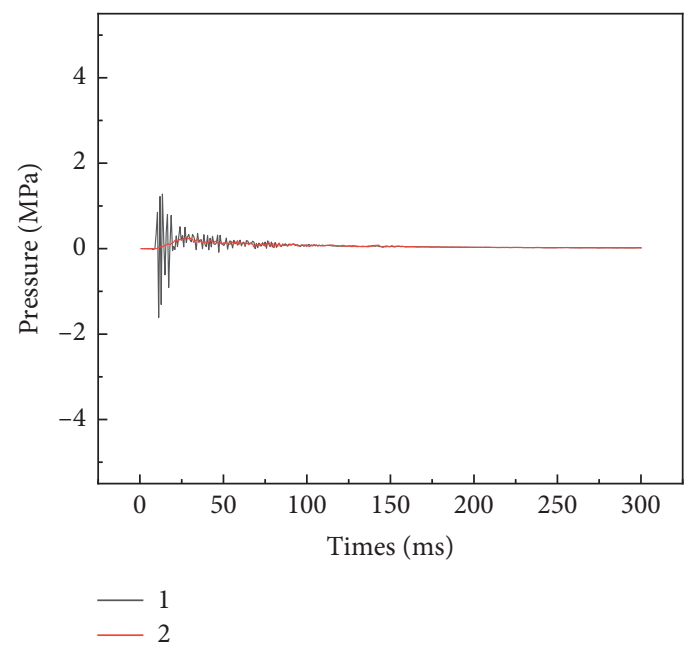

(e)

Figure 11: Pressure-time curve at different distance from charge. (a) $3 \mathrm{~m}$. (b) $5 \mathrm{~m}$. (c) $8 \mathrm{~m}$. (d) $10 \mathrm{~m}$. (e) $15 \mathrm{~m}$.

TABLE 7: Statistical table of peak values of measuring points.

\begin{tabular}{|c|c|c|c|}
\hline Distance from bomb $(\mathrm{m})$ & Direction of explosion & Peak pressure $(\mathrm{MPa})$ & Attenuation ratio (\%) \\
\hline \multirow[b]{2}{*}{15} & 1 & 1.20 & \multirow[b]{2}{*}{75.0} \\
\hline & 2 & 0.30 & \\
\hline \multirow{2}{*}{10} & 1 & 2.00 & \multirow{2}{*}{80.0} \\
\hline & 2 & 0.40 & \\
\hline \multirow{2}{*}{8} & 1 & 3.10 & \multirow{2}{*}{82.3} \\
\hline & 2 & 0.55 & \\
\hline \multirow{2}{*}{5} & 1 & 5.90 & \multirow{2}{*}{86.1} \\
\hline & 2 & 0.82 & \\
\hline \multirow[b]{2}{*}{3} & 1 & 9.43 & \multirow{2}{*}{88.3} \\
\hline & 2 & 1.10 & \\
\hline
\end{tabular}

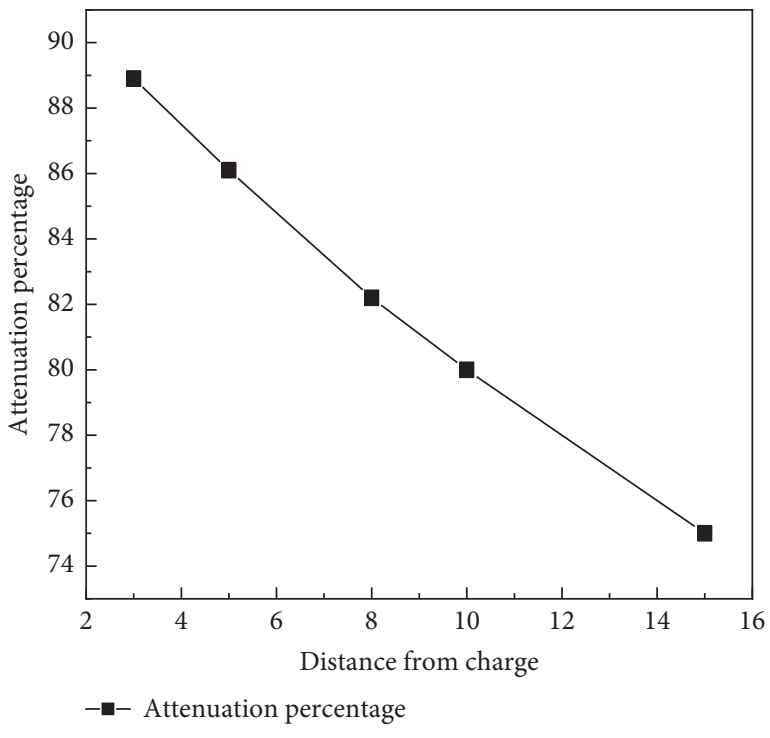

Figure 12: Attenuation percentage diagram of different distance between bubble curtain and charge.

pressure attenuates by $86.1 \%$, and when the distance is $3 \mathrm{~m}$ from the center of the charge, the peak pressure attenuates by $88.3 \%$. As a consequence, it can be seen that the closer the bubble curtain was to the charge, the better the attenuation effect was, and it showed a linear attenuation trend.

\section{Conclusion}

A three-dimensional model was established based on CEL, a coupling method of Eulerian and Lagrangian, and a script was written based on Python to generate natural bubble curtain in order to study the influence of millisecond blasting with different millisecond times and bubble curtain on the propagation law of water hammer wave. In the process of postprocessing, the pressure-time history curve of the typical unit at the distance of $3 \mathrm{~m}$ in the direction of the minimum resistance line of charge was extracted. The peak pressure curves of water hammer waves with different millisecond times in different water depths were extracted. In addition, the reduction effect of bubble curtain at different positions was analyzed, and the following conclusions were obtained:

(1) The peak pressure of the water hammer wave attenuates exponentially with the increase of explosion center distance under different millisecond times. When the millisecond interval was $0 \mathrm{~ms}, 10 \mathrm{~ms}, 20 \mathrm{~ms}, 30 \mathrm{~ms}$, and $40 \mathrm{~ms}$, the peak 
pressure of the water hammer wave was $4.5 \mathrm{MPa}$, 2.1 $\mathrm{MPa}, 2.5 \mathrm{MPa}, 1.8 \mathrm{MPa}$, and $2.2 \mathrm{MPa}$, respectively, in the direction of the minimum resistance line (water depth $10 \mathrm{~m}$ ) and $20 \mathrm{~m}$ away from the charge. With the increase of millisecond time, the attenuation velocity of the water hammer wave increased at first and then decreased, the peak pressure of the water hammer wave in $30 \mathrm{~ms}$ was the smallest, and the attenuation was the fastest.

(2) The peak pressure of water hammer wave in different water depths also showed an exponential attenuation law with the increase of explosion center distance, but the attenuation rate was different. Besides, with the increase of water depth, the attenuation velocity increased at first and then decreased. Taking millisecond blasting $30 \mathrm{~ms}$ as an example, the peak pressure of water hammer wave at the depth of $5 \mathrm{~m}, 10 \mathrm{~m}$, and $20 \mathrm{~m}$ was $1.4 \mathrm{MPa}, 1.8 \mathrm{MPa}$, and $0.8 \mathrm{MPa}$, respectively. The peak pressure of the water hammer wave was the highest and the attenuation speed was the fastest at the water depth of $10 \mathrm{~m}$.

(3) The closer the bubble curtain was to the center of the charge, the better the peak pressure attenuation of the water hammer wave behind the bubble curtain was. In addition, it showed a linear attenuation trend. At the distance of $15 \mathrm{~m}, 10 \mathrm{~m}$, $8 \mathrm{~m}, 5 \mathrm{~m}$, and $3 \mathrm{~m}$ from the bubble wall, the peak pressure attenuation rate behind the bubble curtain was $75.0 \%, 80.0 \%, 82.3 \%, 86.1 \%$, and $88.3 \%$, respectively.

The nonreflection boundary condition was established, but in practice, the amount of concrete impervious wall is located on the bank, and the site is affected by river banks and dams. As a consequence, its boundary conditions may need to be further optimized. Consequently, it is necessary to further study the influence of boundary conditions closer to the field on the attenuation of water hammer pressure, which will contribute to understanding the propagation characteristics of underwater drilling millisecond blasting in more detail.

\section{Data Availability}

The data used to support the findings of this study are available from the corresponding author upon request.

\section{Conflicts of Interest}

The authors declare that there are no conflicts of interest regarding the publication of this article.

\section{Acknowledgments}

This work was supported by the National Natural Science Foundation of China (51874006) and the Anhui Provincial Natural Science Foundation (1808085ME159).

\section{References}

[1] J. Pang, "Numerical simulation of TNT charge explosion in water," Journal of Explosives and Explosives, vol. 32, no. 5, pp. 37-40, 2009, Chinese.

[2] K. Li, X. L. Dong, X. J. Li, Y. G. Wang, and W. Wang, "Determination of JWL parameters from underwater explosion test of spherical explosives by continuous velocity probe," Journal of Energetic Materials, vol. 7, no. 12, pp. 5383-5396, 2014.

[3] C. H. Chen, L. Wu, J. W. Zhao, B. Li, H. Y. Li, and C. J. Li, "Study on the influence of underwater drilling and blasting on the safety of adjacent buildings," Blasting, vol. 33, no. 2, pp. 117-122, 2016, Chinese.

[4] S. F. Qi, X. B. Liu, and Y. C. Li, "Numerical simulation of underwater drilling and blasting," Engineering Blasting, vol. 16, no. 4, pp. 13-17, 2010, Chinese.

[5] D. J. Xie, L. Wu, J. Hong, L. Yuan, M. Cao, and X. H. Luo, "Study on weakening effect of bubble curtain on underwater blasting shock wave," Renmin Changjiang River, vol. 49, no. 8, pp. 72-77, 2018, Chinese.

[6] X. Liu, W. B. Gu, and X. P. Chen, "Numerical simulation study on attenuation characteristics of shock wave in water by bubble curtain," Blasting, vol. 32, no. 3, pp. 79-84, 2015, Chinese.

[7] Z. J. Fan, "Application of millisecond blasting method in underwater reef blasting," Water Transport Engineering, vol. 6, pp. 38-40, 2002, Chinese.

[8] T. Y. Liu, S. T Gong, W. C. Hu, Y. W. Zhong, and L. Wu, "Propagation law of water hammer wave in underwater drilling blasting and reduction effect of bubble curtain on water hammer wave," Blasting Equipment, vol. 49, no. 2, pp. 16-22, 2020, Chinese.

[9] G. Zhao, R. Ji, X. N. Zheng, W. H. Wang, and C. Q. Wu, "Experimental study on shock wave propagation law of underwater explosion of emulsion explosive," Blasting, vol. 28, no. 2, pp. 1-4, 2011, Chinese.

[10] J. F. Si, D. W. Zhong, and L. B. Li, "Analysis of attenuation effect of underwater gas curtain on shock wave based on bubble shape," Explosion and Shock, pp. 1-9, 2021, Chinese.

[11] Y. X. Peng, L. Wu, Y. Su, and C. H. Chen, "Study on the effect of elevation on the prediction of underwater drill and blasting vibration frequency," Geosystem Engineering, vol. 19, no. 4, pp. 170-176, 2016.

[12] Y. Ma, C. Liu, P. Wang, J. Zhu, and X. Zhou, "Blast vibration control in A hydropower station for the safety of adjacent structure," Applied Sciences, vol. 10, no. 18, p. 6195, 2020.

[13] C. Huang, M. Liu, B. Wang, and Y. Zhang, "Underwater explosion of slender explosives: directional effects of shock waves and structure responses," International Journal of Impact Engineering, vol. 130, pp. 266-280, 2019.

[14] Y. Liu, A.-M. Zhang, Z. Tian, and S. Wang, "Investigation of free-field underwater explosion with Eulerian finite element method," Ocean Engineering, vol. 166, pp. 182-190, 2018.

[15] X. Zhai, S. Wu, H. Li, K. Wang, W. Wang, and X. Song, "Experimental and numerical investigation on dynamic behaviors of the concrete wall in underground coal mine with hydraulic blasting demolition," Journal of Vibroengineering, vol. 19, no. 3, pp. 2043-2062, 2017.

[16] W. Gu, Z. Wang, J. Liu et al., "Water-depth-based prediction formula for the blasting vibration velocity of lighthouse caused by underwater drilling blasting," Shock and Vibration, vol. 2017, Article ID 7340845, 9 pages, 2017. 
[17] L. Xin, W. B. Gu, J. Q. Liu, J. L. Xu, T. Cao, M. Filippi et al., "Investigation of the propagation characteristics of underwater shock waves in underwater drilling blasting," Shock and Vibration, vol. 2018, Article ID 9483756, 10 pages, 2018.

[18] W. B. Gu, J. H. Chen, Z. X. Wang, J. Q. Liu, M. Lu, M. Lallart et al., "Experimental study on the measurement of water bottom vibration induced by underwater drilling blasting," Shock and Vibration, vol. 2015, Article ID 496120, 8 pages, 2015.

[19] L. Hammond, Underwater Shock Wave Characteristics of Cylindrical Charges, Defence Science and Technology Organisation, AMRL, DSTO-GD-0029, Australia, 1995.

[20] C. Oucif and L. Muhammad Mauludin, "Numerical modeling of high velocity impact applied to reinforced concrete panel," Underground Space, vol. 4, no. 1, pp. 1-9, 2018.

[21] M. Mokhtari and A. Alavi Nia, "The application of CFRP to strengthen buried steel pipelines against subsurface explosion," Soil Dynamics and Earthquake Engineering, vol. 87, pp. 52-62, 2016. 